\title{
Influenza preparedness in low-resource settings: a look at oxygen delivery in 12 African countries
}

\author{
Janeil Belle ${ }^{1}$, Hillary Cohen ${ }^{2}$, Nahoko Shindo ${ }^{3}$, Matthew Lim ${ }^{4}$, Adriana Velazquez-Berumen ${ }^{5}$, \\ Jean-Bosco Ndihokubwayo ${ }^{6}$, Meena Cherian ${ }^{7}$ \\ ${ }^{1}$ Duke University School of Medicine, Durham, NC, USA \\ ${ }^{2}$ Maimonides Medical Center, Department of Emergency Medicine, Brooklyn, NY, USA \\ ${ }^{3-5,7}$ World Health Organization Headquarters, Geneva, Switzerland, \\ ${ }^{6}$ World Health Organization Regional Office for Africa, Brazzaville, Congo
}

\begin{abstract}
Background: Pandemic influenza poses a serious threat to populations in low and lower-middle income countries that face delays in access to health care and inadequately equipped facilities. Oxygen is first-line therapy for influenza-related hypoxia and a standard component of emergency respiratory resuscitation, yet remains a scarce resource in many countries.

Methodology: A snapshot survey of oxygen supply and associated infrastructure was performed at 231 health centres and hospitals in twelve African countries using the World Health Organization (WHO) Tool for Situational Analysis to Assess Emergency and Essential Surgical Care. WHO Global Initiative for Emergency and Essential Surgical Care, WHO regional and country offices, and local Ministries of Health facilitated data collection from facilities surveyed. Data was stored in the WHO DataCol SQL database and computerized spreadsheet tools were used to generate descriptive statistics.

Results: Ninety-nine (43.8\%) of facilities surveyed reported uninterrupted access to an oxygen source and $55(24.6 \%)$ possessed a fully functioning oxygen concentrator. Electricity was fully available at only $81(35.1 \%)$ health facilities.

Conclusions: In addition to efforts to secure vaccines and antivirals, future global influenza preparedness efforts should include investments in oxygen and associated equipment and infrastructure at first referral health facilities, to minimize morbidity and mortality from influenza in regions with limited medical resources. Increasing oxygen delivery capacity in these areas may also provide long-term, post-pandemic benefits in the management of other medical conditions of significance, including trauma, neonatal pulmonary hypofunction, and HIV-related and childhood pneumonia.
\end{abstract}

Key words: Africa; oxygen; influenza; H1N1; influenza preparedness

J Infect Dev Ctries 2010; 4(7):419-424.

(Received 11 March 2010 - Accepted 23 April 2010)

Copyright (C) 2010 Belle et al. This is an open-access article distributed under the Creative Commons Attribution License, which permits unrestricted use, distribution, and reproduction in any medium, provided the original work is properly cited.

\section{Introduction}

During the emergence of the $2009 \mathrm{H} 1 \mathrm{~N} 1$ pandemic, the World Health Organization (WHO) Clinical Management of Human Infection with new Influenza A H1N1 virus: Initial Guidance Report advised health care providers to screen for hypoxemia at presentation of patients with suspected H1N1 infection and provide supplemental oxygen for oxygen saturations below 90\%. [1] Supplemental oxygen is first-line therapy for initial management of influenza H1N1 hypoxemia and a standard component of emergency respiratory resuscitation. For the past 30 years, oxygen has been included on the WHO List of Essential Medicines, yet it remains a scarce resource in many developing countries today [2-4].
The majority of morbidity and mortality related to influenza H1N1 2009 has been seen in higher income countries; however, influenza poses a great public health threat to populations in low and lower middle income countries (LIC/LMICs), as significant disparities in critical care infrastructure exist among developed and less developed countries [3,5]. LIC/LMICs also possess greater pre-pandemic burdens of respiratory diseases, such as HIV/AIDSrelated pulmonary infections, tuberculosis, and fatal childhood pneumonia than higher income countries [6,7].

Globally, much attention has been given to H1N1 preparedness measures, such as vaccines and antiviral agents, but the benefits of these approaches may not be maximally afforded in LIC/LMICs with limited mechanisms for large-scale vaccination production 
and distribution [8,9]. For these countries, control of pandemic influenza may necessarily focus on clinical management of severe complications and minimization of mortality at first-referral level health facilities. Many of these facilities, however, do not possess adequate resuscitative supplies, such as oxygen or face masks, or the basic infrastructure necessary for the initial management of acute influenza-related respiratory complications $[3,4,10,11]$.

A general lack of oxygen supply has been reported in the past to contribute to mortality rates throughout Africa, including urban centres and capital cities [12]. One survey of district hospitals completed in the United Republic of Tanzania found that $75 \%$ of hospitals had an oxygen supply for less than a quarter of the year [13]. In Kenya, a study on inpatient paediatric care found oxygen demand to exceed supply at the majority of facilities surveyed; oxygen could not be provided to $42 \%$ of children prescribed [14]. A study in Malawi similarly revealed inadequate oxygen supply in paediatric wards in four of five district hospitals; most oxygen concentrator units available were older than 10 years and not in compliance with WHO/United Nations Children's Fund specifications [4]. In 2008, the WHO and Gambian government conducted site visits to assess the treatment of severe pneumonia and observed regular oxygen supplies at only three of 12 districtlevel health facilities [15]. A recent survey of 17 first-referral health facilities in Sierra Leone did not find any facilities with regular oxygen supplies [16]. Beyond the studies reported here, data on the availability of oxygen in Africa is limited. In this study, we present a snapshot assessment of basic oxygen supply and associated equipment, and infrastructure needed in the initial management of influenza $\mathrm{H} 1 \mathrm{~N} 1$ respiratory complications and general emergency respiratory support, in twelve African countries.

\section{Methods}

The WHO Tool for Situational Analysis to Assess Emergency and Essential Surgical Care was used to examine the availability of functioning oxygen cylinders, oxygen concentrators, power generators, and regularity of electricity at firstreferral health facilities in Africa [17]. The survey tool includes a capacity assessment of basic emergency, surgical, and anaesthetic infrastructure and equipment based on the WHO Generic Essential Emergency Equipment List, a checklist of minimal equipment requirements for first-referral health facilities [18].

The following countries participated in the situational analysis: Ethiopia, The Gambia, Ghana, Kenya, Liberia, Malawi, Mali, Nigeria, Sierra Leone, Sao Tome and Principe, United Republic of Tanzania, and Uganda. Allopathic health facilities, community health centres and district, regional, and general hospitals, were identified by the ministries of health of participating governments in collaboration with WHO country offices and WHO Global Initiative for Emergency Essential Care (GIEESC). Data was collected through dissemination of the WHO Tool for Situational Analysis to Assess Emergency and Essential Surgical Care to the identified health facilities by mail, electronic communications, and interviews with health providers and directors of health facilities during WHO GIEESC site visits from 2007-2009. The WHO Tool for Situational Analysis to Assess Emergency and Essential Surgical Care was made available in English to all participating health facilities [17]. Completed surveys were returned to WHO Country Offices and submitted to WHO Headquarters in Geneva. Data was entered and stored in the WHO DataCol SQL database. Frequencies and proportions reported were generated using computerized spreadsheet tools.

\section{Results}

Twelve sub-Saharan African countries and 231 health facilities were represented in the survey. Table 1 summarizes the number of responses by country. Eighty-eight $(38.1 \%)$ of the facilities surveyed were primary health care centres, $53(22.9 \%)$ were private or non-governmental sector hospitals, 53 (22.9\%) were district hospitals, $19(8.2 \%)$ were regional or provincial hospitals, and $18(7.8 \%)$ were general hospitals (Table 2).

Table 1. Types of health facilities surveyed in the twelve countries participating in the study.

\begin{tabular}{|l|c|}
\hline Health Centers & 88 \\
\hline Private/non-governmental /mission hospitals & 53 \\
\hline District hospitals & 53 \\
\hline Provincial hospitals & 19 \\
\hline General hospitals & 18 \\
\hline TOTAL & $\mathbf{2 3 1}$ \\
\hline
\end{tabular}


Table 2. Number and percentage [n, (\%)] of health facilities that reported at least one of the items below was either always, sometimes, or not fully functioning and available for use at the time of inquiry.

\begin{tabular}{|l|c|l|l|l|c|l|}
\hline & Electricity & Generator & $\begin{array}{l}\text { Any oxygen } \\
\text { source }\end{array}$ & $\begin{array}{l}\text { Oxygen } \\
\text { Cylinder }\end{array}$ & $\begin{array}{l}\text { Oxygen } \\
\text { Concentrator }\end{array}$ & $\begin{array}{l}\text { Face mask } \\
\text { and tubing }\end{array}$ \\
\hline Always available & $81(35.1)$ & $127(56.7)$ & $99(43.8)$ & $66(29.1)$ & $55(24.6)$ & $75(34.3)$ \\
\hline Sometimes available & $112(48.5)$ & $59(26.3)$ & $71(31.4)$ & $55(22.9)$ & $64(28.6)$ & $79(37.6)$ \\
\hline Not available & $38(16.5)$ & $38(17.0)$ & $56(24.8)$ & $109(48.0)$ & $105(46.9)$ & $65(31.0)$ \\
\hline
\end{tabular}

Of the 231 health facilities surveyed, $99(43.8 \%)$ reported access to an oxygen source and 75 (34.3\%) had at least one face mask and tube set always available. Sixty-six (29.1\%) of the responding facilities had regular access to at least one oxygen cylinder and 55 (24.6\%) possessed a fully functioning oxygen concentrator. Electricity, however, was fully available in only $81(35.1 \%)$ of the facilities surveyed and $127(56.7 \%)$ had a backup power generator. Only $60(42.0 \%)$ of the 143 facilities reporting unstable or lack of electricity and status of back-up generators had functioning generators available for use (Table 2).

\section{Discussion}

Since the first laboratory-confirmed case of H1N1, there have been more than 400,000 affected persons reported in more than 214 countries and territories worldwide [19,20]. Severe complications have been observed in individuals with H1N1 influenza and these patients often require hospitalization. The WHO reports a hospitalization rate of $2-10 \%$ of confirmed $\mathrm{H} 1 \mathrm{~N} 1$ infections and 2-9\% fatality rate among hospitalized patients [19]. Complications include primary viral pneumonia and acute respiratory distress syndrome (ARDS); exacerbation of chronic medical conditions such as asthma, chronic obstructive lung disease, and congestive heart failure; neurological complications such as encephalopathy and seizures; secondary invasive bacterial infection; sepsis; and death [21,22]. Most hospitalized cases of H1N1 appear to be due to acute primary viral pneumonia, with some progressing to potentially fatal diseases including, refractory hypoxemia due to ARDS and multi-organ dysfunction requiring ICU management $[21,23]$.

The importance of respiratory resuscitation and oxygen administration for the management of pandemic H1N1 complications was recognized early in a retrospective chart review of 18 cases of H1N1- related pneumonia occurring in Mexico in March 2009 [24]. Of the 18 cases, 10 patients had a median oxygen saturation of $71 \%$ and were intubated within 24 hours of admission [24]. Twelve patients required mechanical ventilation during the disease course and 7 died [24]. Median $\mathrm{PaO}_{2}$ was $55.4 \mathrm{mmHg}$ in surviving patients and $41.5 \mathrm{mmHg}$ in patients that succumbed due to complications from H1N1 influenza [24]. Oxygen administration appears to be crucial in the management of severe pulmonary manifestations of influenza H1N1 infection.

The WHO Tool for Situational Analysis to Assess Emergency and Essential Surgical Care was used in this study to provide a snapshot assessment of oxygen availability in sub-Saharan Africa in order to evaluate the capacity to provide basic respiratory resuscitation that may be required in the management of acute respiratory complications related to influenza infection [17]. The skeleton survey presented is not a comprehensive evaluation of the availability of all respiratory equipment and supplies needed to manage all influenza-related respiratory complications described. The findings are reported to assess oxygen delivery capacity in Africa and advocate for the consideration of low-resource settings in pandemic planning at all levels of governance.

Health policy development based on the data reported here should consider study limitations including non-uniform methods of data collection and lack of response integrity validation for surveys completed without site visits. The survey instrument used in this study has been employed in previously published studies on emergency care resources in developing countries and was subjected to initial pilot administration and revision $[15,16,25,26]$.

The situational analysis of oxygen delivery capacity in the twelve sub-Saharan African countries presented here demonstrates inadequate access to oxygen similar to prior studies reporting limited 
Table 3. Ideal attributes of oxygen delivery devices for limited-resource settings in low and low middle income countries.

\title{
Oxygen concentrator specifications for resource-limited settings
}

\author{
Portable \\ Robust \\ - fall-resistant ${ }^{28}$ \\ - withstands $40^{\circ} \mathrm{C}$ and $100 \%$ relative humidity ${ }^{28}$ \\ Electricity-independent power supply option \\ User-friendly interface \\ Low-maintenance \\ Easily calibrated \\ Meets international standardization
}

oxygen supplies at district hospitals in Africa. Most notable is the lack of access to functioning oxygen concentrators and disparity in the availability of concentrators and the electricity needed for operation $[27,28]$.

The WHO recommends oxygen concentrators to be used as the primary oxygen supply for developing countries, but for many LIC/LMICs, pressurized oxygen cylinders are the method of choice for oxygen delivery because they are less expensive and easier to use than concentrators [27,28]. Transportation difficulties, exhaustible oxygen supply, and restricted patient use (1 cylinder per patient) outweigh initial savings, which leads to frequent shortages $[13,28]$. The average cost of an oxygen concentrator and yearly maintenance is about half as much as the cost associated with cylinder use [28].

Oxygen concentrators are ideal for use in pandemic settings given advantages in cost and efficiency of oxygen delivery (per patient) over oxygen cylinders, but these benefits may be offset by the cost of electricity and additional personnel training needed to operate the device. Affordable, easily-maintained, electricity-independent, oxygen delivery machines are desperately needed to scale up oxygen availability in low-resource areas worldwide. Table 3 outlines preferred specifications for oxygen delivery devices for low-resource settings. Development of an oxygen concentrator module with a detachable pulse oximetry unit would optimize clinical management of pandemic influenza H1N1 in low-resource areas.

The most severely affected areas during the 2009 influenza H1N1 pandemic were high- and middleincome nations: United States, Canada, Mexico,
Australia, New Zealand, Chile, Argentina, Brazil, United Kingdom, and Thailand. As the virus spread, however, significant morbidity and mortality was also reported in India, South Africa, Peru and Colombia [5]. Interrupted oxygen supplies, irregular electricity, lack of backup generators, and poor access to functioning resuscitative equipment is a likely scenario in less-developed countries which may significantly impede influenza countermeasures and could result in disproportionately higher morbidity and mortality in these areas. In order to adequately prepare for influenza pandemics, preparedness strategies for medically underserved areas must be prioritized.

Several health facilities in resource-constrained areas in Egypt and Papua New Guinea have reported successful institution of oxygen delivery systems using oxygen concentrators [29,30]. Oxygen concentrators and pulse oximeters were introduced in five hospitals in Papua New Guinea for US\$51 per patient and resulted in a reduction in paediatric pneumonia mortality from $4.97 \%$ [95\%CI 4.5-5.5] to 3.22 [95\%CI 2.7-3.8] in 27 months [29]. Oxygen concentrators can be an effective, low-cost, solution to oxygen shortages for developing countries, with a return on investment reported to be achieved in one to two years [12].

Due to the efficient transmissibility of H1N1 and the potential risk of highly virulent pandemic strains in the future, influenza control strategies should also aim to reduce morbidity and mortality as well as infection. In addition to vaccines and antiviral agents, governments in countries with limited medical resources should also direct investments toward the provision of basic respiratory resuscitation supplies and infrastructure at first-referral health facilities. 
Increasing oxygen delivery capacity in LIC/LMICs will not only mitigate health impacts during an influenza pandemic, but affords durable, wideranging benefits for community health. Oxygen is a mainstay therapy in most respiratory emergencies, including trauma, neonatal resuscitation, and severe childhood pneumonia, with the latter being the leading cause of death in children worldwide [14]. Development and distribution of setting-appropriate oxygen delivery devices in low-resource health facilities should be prioritized in the global defense against pandemic influenza. Such a strategy will ultimately benefit the management of other respiratory diseases, the provision of safe surgical services (trauma, obstetrics, anesthesia), and aid overall health system strengthening.

\section{Acknowledgements}

We would like to acknowledge the WHO Country Offices and ministries of health in the participating countries and members of the Global Initiative for Emergency and Essential Surgical Care who have contributed to data collection.

\section{References}

1. World Health Organization (2009) Clinical management of human infection with new

influenza A (H1N1) virus: initial guidance. May 2009. Available:

http://www.who.int/csr/resources/publications/swineflu/clini cal_management H1N1_21_May_2009.pdf. Accessed 14 July 2009.

2. World Health Organization (2005) Comparative Table of Medicines on the WHO Essential Medicines List from 19772005. Available:

http://www.who.int/medicines/publications/essential medicines/compar_table_who_edls.xls. Accessed 14 July 2009.

3. Fowler R, Adhikari NK, Bhagwanjee S (2008) Clinical review: Critical care in the global context-disparities in burden of illness, access, and economics. Crit Care 12: 225.

4. Enarson P, La Vincente S, Gie R, Maganga E, Chokani C (2008) Implementation of an oxygen concentrator system in district hospital paediatric wards throughout Malawi. Bull World Health Org 86: 344-348.

5. World Health Organization (2009) Pandemic (H1N1) 2009update $68 . \quad$ Available: http://www.who.int/csr/don/2009_10_02/en/index.html. Accessed 7 October 2009.

6. World Health Organization (2008) WHO guidelines for emergency health interventions in community settings: reducing excess mortality from common illnesses during an pandemic. Available: http://www.who.int/diseasecontrol_emergencies/ common_illnesses2008_6.pdf. Accessed 14 July 2009.

7. Oshitani H, Kamigaki T, Suzuki A (2008) Major Issues and Challenges of Influenza Pandemic Preparedness in Developing Countries. Emerg Infect Dis 16: 875-80.

8. Gallaher W (2009) Towards a sane and rational approach to the management of influenza H1N1. Virol J 6: 51.
9. Chaturvedi, S (2009) Pandemic Influenza: Imminent Treat, Preparedness and the Divided Globe. Ind Ped 46: 115-121.

10. Dunser MW, Baelani I, Ganbold L (2006) A review and analysis of intensive care medicine in the least developed countries. Crit Care Med 34: 1234-1242.

11. Graham S, English M, Tabish H, Enarson P, Duke T (2008) Challenges to improving case management of childhood pneumonia at health facilities in resource-limited settings. Bull World Health Org 86: 349-55.

12. L'Her P, Tchoua R, Hutin R, Soumbou A, Yos P, Saissy, JM (2006) The problem of oxygen in developing countries. Med Trop 66: 631-8.

13. World Health Organization (2004) Surgical Care at the District Hospital. Geneva: World Health Organization.1519.

14. English M, Esamai F, Wasunna A, Were F, Ogutu B, Wamae A, Snow RW, Peshu N (2004) Assessment of inpatient paediatric care in first referral level hospitals in 13 districts in Kenya. Lancet 363: 1948-53.

15. Hill S, Nije O, Sanneh M, Jallow M, Peel D, Njie M, Weber M, Hill PC, Adegbola RA, Howie SR. (2009) Oxygen for treatment of severe pneumonia in The Gambia, West Africa: a situational analysis. Intl $\mathrm{J}$ Tub and Lung Dis. 13: 587-93.

16. Kingham T, Kamara T, Cherian M, Gosselin R, Simkins M, Meissner C, Foray-Rahall L, Daoh KS, Kabia SA, Kushner AL (2009) Quantifying Surgical Capacity in Sierra Leone: A guide for improving surgical care. Arch Surg 144: 122127.

17. World Health Organization. World Health Organization Tool for Situational Analysis of Emergency and Essential Surgical Care. Available:http://www.who.int/surgery/ publications/ QuickSitAnalysisEESCsurvey.pdf. Accessed 6 October 2009.

18. World Health Organization. WHO Generic Essential Emergency Equipment List. Available: http://www.who.int/surgery/publications/EEEGenericListFo rmatted\%2006.pdf. Accessed 25 June 2009.

19. World Health Organization (2009) Pandemic influenza A (H1N1) 2009 virus vaccine

- conclusions and recommendations from the October 2009 meeting of the immunization Strategic Advisory Group of Experts. 4 December 2009. http://www.who.int/wer/2009/wer8449.pdf. Accessed 1 January 2010.

20. World Health Organization. Weekly Epidemiology Report. Pandemic (H1N1) 2009 - update 106. 25 June 2010. Available: http://www.who.int/csr/don/2010_06_25/ Accessed 29 June 2010.

21. World Health Organization (2009) Weekly Epidemiological Record- Strategic Advisory Group of Experts on Immunization -report of the extraordinary meeting on the influenza A (H1N1) 2009 pandemic. July 2009. 84:30; 301308.

Available:

http://www.who.int/wer/2009/wer8430/en/index.html. Accessed 5 September 2009.

22. Thorner A (2009) Epidemiology, clinical manifestations, and diagnosis of swine H1N1 influenza A. Up To Date. Accessed 15 July 2009.

23. Jain S, Kamimoto L, Bramley A, Schmitz A, Benoit S, Louie J, Sugerman D, Druckenmiller J, Ritger K, Chugh R, Jasuja S, Deutscher M, Chen S, Walker J, Duchin J, Lett S, Soliva S, Wells E, Swerdlow D, Uyeki T, Fiore AE, Olsen S, Fry A, Bridges C, Finelli L (2009) Hospitalized patients with 2009 H1N1 influenza in the United States, April-June 
2009. N Engl J Med 361: 1-9.

24. National Institute of Respiratory Diseases (INER) Working Group on Influenza. (2009) Pneumonia and Respiratory Failure from Swine-Origin Influenza A (H1N1) in Mexico. N Engl J Med 361:680-89.

25. Contini S, Taqdeer A, Cherian M, Shokohmand AS, Gosselin R, Graaff P, Noel L (2010) Emergency and essential surgical services in Afghanistan: still a missing challenge. World J Surg 34: 473-9

26. Taira B, Cherian M, Yakandawala H, Kesavan R et al. (2010) Survey of Emergency and Surgical Capacity in ConflictAffected Regions of Sri Lanka. World J Surg 34: 428-32.

27. Perrelet A, Zellweger J, Talla I, Ndiaye Y, Gautier E, Gehri $M$ (2005) The oxygen concentrator: an appropriate technology for treating hypoxaemic children in developing countries. Int J Tuberc Lung Dis 8: 1138-1141.

28. Dobson M (2001) Oxygen concentrators and cylinders. Int J Tuberc Lung Dis 5: 520-23.

29. Duke T, Wandi F, Jonathan M, Matai S, Kaupa M, Saavu M, Subhi R, Peel D . (2008) Improved oxygen systems for childhood pneumonia: a multi-hospital effectiveness study in Papua New Guinea. Lancet 9646:1328-33.

30. Dobson MB, Peel D, Khallaf N (1996) Field trial of oxygen concentrators in upper Egypt. Lancet 347: 1597-99

\section{Corresponding author}

Dr. Meena N. Cherian

World Health Organization

Department of Essential Health Technologies

(HSS/EHT/CPR)

20 Avenue Appia

1211, Geneva 27

Switzerland

Tel: +4122791 1858

Fax: +41227914836

Email: cherianm@who.int

Disclaimer: The authors include staff members of the World Health Organization. They are responsible for the views expressed in this publication and do not necessarily represent the decisions or stated policy of the World Health Organization

Conflict of interests: No conflict of interests is declared. 